\title{
Cross-border regional innovation systems: conceptual backgrounds, empirical evidence and policy implications
}

\section{Teemu Makkonen \& Stephan Rohde}

To cite this article: Teemu Makkonen \& Stephan Rohde (2016): Cross-border regional innovation systems: conceptual backgrounds, empirical evidence and policy implications, European Planning Studies, DOI: 10.1080/09654313.2016.1184626

To link to this article: http://dx.doi.org/10.1080/09654313.2016.1184626

Published online: 17 May 2016.

Submit your article to this journal $\pi$

Џll Article views: 23

Q View related articles $\longleftarrow$

View Crossmark data \lceil 


\title{
Cross-border regional innovation systems: conceptual backgrounds, empirical evidence and policy implications
}

\author{
Teemu Makkonen ${ }^{\mathrm{a}, \mathrm{b}}$ (1) and Stephan Rohde ${ }^{\mathrm{c}}$ \\ ${ }^{\mathrm{a} S c h o o l}$ of Hospitality and Tourism Management, University of Surrey, Guildford, UK; ${ }^{\mathrm{b}}$ Department of Business \\ and Economics, University of Southern Denmark, Sønderborg, Denmark; 'International Institute of \\ Management and Economic Education, Europa-Universität Flensburg, Flensburg, Germany
}

\begin{abstract}
The concept of cross-border regional innovation systems (CBRIS) surfaced in the literature on economic geography through discourses that highlighted the need for broadening innovation systems to cross-border contexts. Since these early discussions, the theoretical backgrounds of CBRIS have been elaborated through notions of geographical scale, proximity and related variety in a range of conceptual papers proposing CBRIS as a comprehensive framework for analysing regional cross-border integration. However, the empirical literature on CBRIS has failed to keep up with the advances in conceptualization. This paper discusses the reasons behind this mismatch, which means that the concept still rests upon and draws policy suggestions based on a thin evidence base. Directions for further research are pointed out by underlining the need for holistic empirical validation of the concept together with the need of understanding how suggested policy measures based on CBRIS reasoning have been implemented in border regions, and their effectiveness in promoting cross-border integration.
\end{abstract}

\section{ARTICLE HISTORY}

Received 3 November 2015

Revised 29 March 2016

Accepted 26 April 2016

\section{KEYWORDS}

Cross-border region; geographical scale; integration; proximity; regional innovation system; related variety

\section{Introduction}

Innovation is discussed as an important driver of economic development and competitiveness in various strands of literature (McCann \& Ortega-Argilés, 2013; Tödtling \& Trippl, 2005). Accordingly, in the contemporary economic geography literature, there is a widespread agreement on the usefulness and importance of the systems of innovation approach as an analytical framework for innovation studies. It allows a differentiated investigation of territorial innovation activity, which is considered as a systemic, interactive and integrative economy-wide process (Asheim \& Vang, 2006; Lundvall, 2007). However, in most cases, the empirical and theoretical literatures on innovation systems have focused on national and regional scales, that is, 'national innovation systems' (NIS) and 'regional innovation systems' (RIS), thereby excluding the possibilities of developing innovation systems in the context of cross-border regions (CBR). The notion that the long-term innovative and competitive success of CBR largely depends on their ability to create these common innovation systems, 
led to the coining of a new innovation systems concept (Trippl, 2010), ${ }^{1}$ namely 'crossborder regional innovation systems' (CBRIS). ${ }^{2}$ During the following five years, the concept has been further developed and used as an empirical framework in various studies (Appendix).

Despite the growing interest in this topic, the theoretical development of the concept and the state of the art in empirical analyses of CBRIS have not been mapped and discussed (Rohde, in press). Thus, until now, it has remained unclear how effectively the concept fits the realm of empirical analysis and whether and how the concept has seen major theoretical developments since its introduction to the economic geography literature. This research gap motivates our approach to conduct a systematic review of CBRIS and to discuss the existing body of work. First, Section 2 explains the methodological procedure of gathering relevant literature and its systematization. Second, Section 3 identifies and analyses the literature in light of (1) theoretical backgrounds and the key literature on CBRIS, (2) its relationship to studies on proximity and related variety, (3) its varying dimensions and (4) stages of CBRIS integration, (5) the geographical scale, (6) sectoral scope and (7) policy implications. Third, the reviewed literature leads us to discuss critically the intersection between the conceptual and the empirical literature on CBRIS and suggest directions for further research in Section 4. Finally, the literature review ends with concluding remarks and an agenda for further research in Section 5.

\section{Methodological background}

The reviewed literature, in English, was gathered from the Scopus database of social sciences and humanities by using the word searches 'regional innovation system' and 'cross-border' in title, keywords and abstract. These specific word searches were applied to screen the research that has CBRIS among the core concepts. Scopus was chosen as the initial database because it includes a wide range of peer-reviewed literature. This was supplemented by similar procedures in Google Scholar to take into account books and journals that are not covered by the Scopus database. However, conference and working papers were excluded from the analysis, since most of these have been eventually published as peer-reviewed research outcomes in journals or contributions to edited books. The restriction to peer-reviewed literature helps ensure a certain scientific quality of relevant results. Identified literature was screened and subdivided into three main groups: (1) 'Early CBRIS literature' contains studies that were published before 2010, that is, before the publication of the pioneering article on CBRIS by Trippl (2010), (2) 'Conceptual groundwork of CBRIS, discussion and further developments' covers literature that provides conceptual contributions to the CBRIS concept and (3) 'Empirical validations of CBRIS' includes literature that delivers empirical insights with regard to the CBRIS concept. The literature of each group was systematically prepared in tabular form with regard to the applied method, data collection, geographical scale, sectoral scope, proximity type, studied dimension(s) and selected conclusions. This systematic review allows the drawing of a profile of CBRIS, focusing on seven central themes in the conceptual and empirical literature that were outlined in the introduction. The reviewed studies, covering the CBRIS literature up until the end of December 2015, are presented in the Appendix. 


\section{CBRIS in conceptual and empirical literature}

\subsection{Theoretical backgrounds and key literature of CBRIS}

The theoretical backgrounds of CBRIS are embedded in the literature on industrial districts (Brusco, 1982), clusters (Porter, 1990), learning regions (Maskell \& Törnqvist, 1999) and of course in the work on NIS and RIS (Cooke, 1992; Lundvall, 1992). In particular the discussion on CBRIS refers to the literature on RIS, where four distinct elements (or dimensions) can be identified (Figure 1): (1) the knowledge generation and diffusion subsystem, including research institutes, educational bodies and technology transfer organizations; (2) the knowledge application and exploitation subsystem, that is the companies located in the region; (3) the regional policy subsystem, including local public authorities; and (4) socio-cultural factors, including formal (e.g. laws and regulations) and informal (e.g. routines, conventions and habits) institutions (Kiryushin, Mulloth, \& Iakovleva, 2013; Trippl, 2010). However, external influences (including international institutions and the NIS) also make a significant contribution to the functioning of RIS for example, through direct funding and through innovation and science policies (Autio, 1998). Additionally, other RIS might act as competitors and/or collaboration partners (Makkonen \& Inkinen, 2014). In an optimal case, there are intensive local interactions between, and also within, the knowledge generation and diffusion and the knowledge application and exploitation subsystems that are supported, promoted and fostered by the regional policy subsystem leading to heightened regional innovativeness and competitiveness (Tödtling \& Trippl, 2005). The socio-institutional factors, in turn, are extremely important in determining and moulding the prevalent local cooperation behaviour, patterns and networks of regional actors (Trippl, 2010).

It was precisely the adaptation of the RIS into the CBR context which created the concept of CBRIS (Trippl, 2010). Consequently, the critique that can be voiced on the concept of CBRIS is in many ways analogous to the one placed on RIS (Doloreux \& Parto, 2005; Makkonen \& Inkinen, 2014; Uyarra \& Flanagan, 2010). Most fundamentally

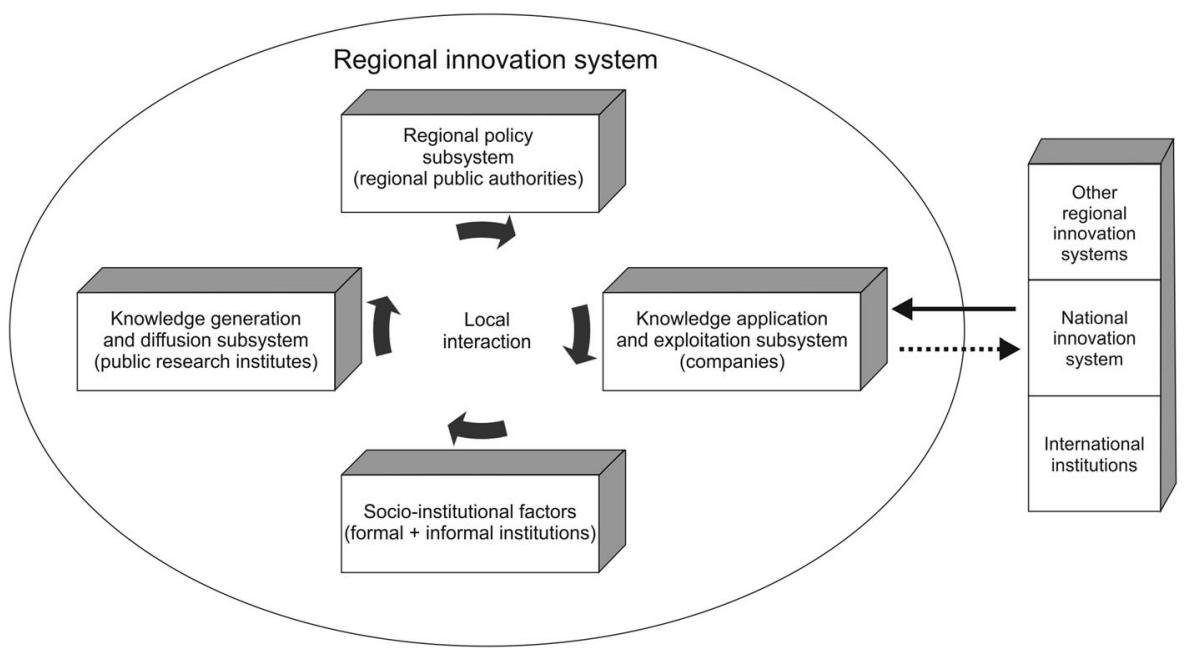

Figure 1. RIS and its subsystems (modified from Autio, 1998; Kiryushin et al., 2013). 
there is a 'definition confusion', that is, there is no consensus on how one should delineate a RIS (if one sees one) and its constituting components. Equally, the exact way how institutions should interact in different RIS has remained ambiguous. When the RIS is applied in a cross-border context, it is likely that the system has two separate, but potentially wellintegrated, parts. For example, in the case of a regional policy subsystem, there are separate regional public authorities working on developing their respective sides of the border. These two may have coordinated policies for CBR development or there might even be a separate administrative organization in charge of cross-border cooperation (CBC). However, this does not usually mean that the individual regional public authorities would be abolished. Accordingly, a CBR belongs to two separate NIS: the local knowledge generation and diffusion as well as knowledge application and exploitation subsystems might be strongly embedded in their respective regional or national levels. Similarly, on the adjacent side of the border, socio-institutional factors commonly differ significantly. Thus, the border might, and normally does, create barriers that hamper local interaction in the CBRIS context. However, at the same time, the differences that these barriers create can also be seen as opportunities for combining unexploited synergies that could lay the foundations for CBR economic growth (Jauhiainen, 2014; Lundquist \& Trippl, 2013).

There are a few other early papers (Hansen \& Hansen, 2006; Hassink, Dankbaar, \& Corvers, 1995; Krätke \& Borst, 2007; Moodysson \& Jonsson, 2007) which, while not applying an innovation systems approach, also deal with innovation at the cross-border level. However, arguably the papers by Koschatzky (2000), Coenen, Moodysson, and Asheim (2004) and Lundquist and Winther (2006) are the clearest examples where an innovation system framework had been adapted when analysing CBR, prior to the first detailed conceptualization of CBRIS. Additionally, at least to the authors' knowledge, the paper by Coenen et al. (2004) is the first instance ${ }^{3}$ where the term CBRIS appeared. Thus, although RIS and CBR had been discussed in a few earlier empirical studies, conceptually the topic was first formulated by Trippl (2010) and later developed by Lundquist and Trippl (2013) and Weidenfeld (2013). Jauhiainen (2014) has subsequently summarized some of the key issues of CBRIS in a policy briefing. Following the conceptual literature, CBRIS have also been used as an analytical framework in various empirical studies (Bijaoui, Sultan, \& Tarba, 2011; Hansen, 2013; Kiryushin et al., 2013; Makkonen, 2015; van den Broek \& Smulders, 2014, 2015).

\subsection{Proximity, related variety and CBRIS}

The arguments made by the 'proximity school' (Boschma, 2005) have been a major catalyst for the conceptualization of the CBRIS concept. The literature on proximity recognizes several different types of proximities, since just being geographically close does not automatically lead to intensive cooperation networks and high levels of innovative outputs (Koschatzky, 2000; Trippl, 2012). In essence, this recognition includes a division between functional and relational proximity. Relational proximity is an umbrella term for all non-spatial proximity types, including cognitive, cultural, institutional, social, organizational and technological. In contrast, functional proximity refers to the geographical or physical dimension of distance understood through travel times and transportation costs rather than through mere Euclidean distance (Coenen et al., 2004). The various dimensions of relational proximity have been defined in earlier literature (Boschma, 
2005; Hussler, 2004; Knoben \& Oerlemans, 2006) in terms of similarity of knowledge bases (cognitive proximity), shared cultural backgrounds such as language and religion (cultural proximity), similarity of formal rules and informal constraints (institutional proximity), similarity of organizational contexts (organizational proximity), personal trust-based relationships (social proximity) and shared technological experiences (technological proximity).

However, there are differences in how some of these terms are used and understood: for example, technological proximity is also related to the similarity of knowledge bases which is equally relevant for cognitive proximity (Knoben \& Oerlemans, 2006). In contrast, some scholars refer to functional distance as the level of similarity of innovation performance (Maggioni \& Uberti, 2007). Thus, the definitions that describe the different types of proximity significantly overlap with each other and according to Aguilera, Lethiais, and Rallet (2015, p. 799) are still 'poorly defined and even more poorly measured'. Nevertheless, the abundant empirical literature on proximity and innovation at the firm, and varying regional levels (Broekel, 2015; Heringa, Horlings, van der Zouwen, van den Besselaar, \& van Vierssen, 2014), has generally agreed that 'proximities have a significant complementary role in generating an important flow of knowledge across regions' (Paci, Marrocu, \& Usai, 2014, p. 9). This signifies the importance of proximity in the conceptual debates on CBRIS. However, the empirical results produced, with varying distinctions and measures of proximity, by these studies have only partly been able to confirm the arguments about the importance of proximity. There seem to be significant differences in how the innovation performance of specific industries and regions is affected vis-à-vis proximity.

In response to these findings, recent conceptual discussions of proximity and innovation have proposed that, instead of high levels of proximity, an optimum amount - neither too small nor too large distance - of cognitive proximity between regions is necessary for real learning opportunities to be present (Boschma \& Weterings, 2005). This is termed 'related variety'. The discussion on related variety has been adapted into the CBRIS literature (Jauhiainen, 2014; Lundquist \& Trippl, 2013; Trippl, 2010) based on the following logical notion: if the opposing sides of the border are too similar, there is little to learn from each other, and if they are too different there are no gains from synergies. ${ }^{4}$ Thus, the commonly hypothesized inverted U-curve between cognitive proximity and innovation.

The empirical literature on related variety on the national and regional levels has commonly been interested in how varying regional industrial and sectoral mixes impact on employment and economic growth (Hartog, Boschma, \& Sotarauta, 2012; van Oort, de Geus, \& Dogaru, 2015). These studies generally confirm the positive economic effects of related variety, whereas the empirical literature on related variety and its impacts on firm-level and regional innovativeness is still inconclusive. For example, Nooteboom, van Haverbeke, Duysters, Gilsing, and van den Oord (2007) and Broekel and Boschma (2012) have presented evidence that the hypothesized inverted U-shaped effect of cognitive distance on the innovation performance of alliances between firms can be confirmed. In contrast, summarizing the results from recent studies on proximity and innovation, Heringa et al. (2014) found no evidence to support the statements that proximity would follow this inverted U-curve. Thus, there is still lack of clarity as to what is exactly 'close enough' and/but 'far enough' for successful innovative outcomes in terms of cognitive proximity. Evidently there are no one-size-fits-all solutions due to the likely 
temporal, geographical and sectoral variations of optimal levels of cognitive proximity. Therefore, there is a need to empirically test the concept of related variety with a more extensive geographical and sectoral coverage for determining whether the results provided by the existing case studies are generalizable (Caragliu, de Dominicis, \& de Groot, 2016).

While it is relatively easy to incorporate multiple types of proximity into the conceptual discussion and underline how they are intertwined, it is empirically far more difficult to differentiate between these distinct but still closely related concepts. This incurs a risk of conceptual overlap (Coenen et al., 2004). Accordingly, the discussion of related variety, while conceptually alluring, is hard to pinpoint empirically, and has yet to be verified empirically in the context of CBRIS. Consequently, the empirical literature on CBRIS has concentrated on studying a single, or few types of, proximity including cognitive distance (Makkonen, 2015), geographical proximity or physical barriers (Bijaoui et al., 2011; Hansen, 2013; Kiryushin et al., 2013) and institutional gaps (van den Broek \& Smulders, 2014, 2015). What is noticeable is that in the early literature on CBRIS, the empirical validations of proximity in CBR were actually more diverse and ambitious than they have been recently (Appendix). For example, Koschatzky (2000) and Coenen et al. (2004) have underlined the importance of cultural and institutional proximity in comparison to the modest role played by spatial distance. Thus, despite the need for more research on the subjects (Lundquist \& Trippl, 2013), the subsequent empirical literature on CBRIS has been unable to produce new significant insights or novel findings supporting the conceptualization of proximity and related variety.

\subsection{Key determinants for the development of CBRIS}

The first conceptualization of the CBRIS concept also included a division into five distinct dimensions, closely related to the subsystems of RIS and to the discussion of varying types of proximity (Trippl, 2010): (1) knowledge infrastructure (science base), (2) business (economic structure/specialization pattern), (3) relational (nature of linkages), (4) socio-institutional (institutional set-up) and (5) governance dimensions (policy structures). Later Lundquist and Trippl (2013) modified and renamed these dimensions (shown in brackets above) and added a sixth dimension, namely accessibility, to the typology of CBRIS. Relatedly, Weidenfeld (2013) has suggested that tourism increases crossborder mobility, which can potentially enable knowledge transfer and innovation in CBRIS. In essence, a strong CBRIS can emerge if the CBR hosts an advanced scientific base and a well-developed innovation-related infrastructure (knowledge infrastructure dimension), the companies on both sides of the border are innovative (business dimension), there are economic relations and processes of collective learning across the border (relational dimension) and certain levels of cultural, social and institutional types of proximity present in the CBR (socio-institutional dimension) and the regions have sufficient political autonomy to carry out coordinated CBRIS policies (governance dimension) (Trippl, 2010). In line with this, CBRIS should have a certain degree of physical proximity (accessibility dimension) (Lundquist \& Trippl, 2013).

Taken together, these dimensions help to explain the stages of integration (discussed below), innovativeness and competitiveness of CBR. However, empirically no study thus far has explored all these dimensions together, an issue that Lundquist and Trippl (2013) deem to be extremely important for further developments of the concept. 
Instead, the subsequent empirical literature has concentrated only on individual aspects of CBRIS and on a few closely connected dimensions: van den Broek and Smulders (2014, 2015) have analysed the socio-institutional and governance dimensions, whereas Hansen (2013) and Makkonen (2015) have explored the knowledge infrastructure and relational dimensions. Therefore, the concept has yet to be validated as a whole. This underlines that there is a significant need for the first empirical paper which comprehensively deals with the varying dimensions of CBRIS.

\subsection{Stages of CBRIS integration}

Building on the different dimensions of CBRIS, the varying stages of CBRIS integration were first introduced by Lundquist and Trippl (2013), and later discussed and summarized by, for example, Jauhiainen (2014). They include (i) weakly integrated, (ii) semi-integrated and (iii) strongly integrated systems. The three stages can be regarded as ideal cases, whereas in the real world it is much more likely that CBRIS will display varying levels of integration on different dimensions: for example, high accessibility but a low level of integration in the business dimension. Therefore, CBRIS do not so much flip between stages, but rather can gradually evolve from one stage of integration to another (van den Broek \& Smulders, 2014).

Weakly integrated systems have only relatively low levels of cross-border interaction and few cross-border innovation linkages. However, departing from the original illustration, Lundquist and Trippl (2013, p. 455) actually introduced two varying CBRIS for the weakly integrated stage: those CBRIS with no synergies (Ia) and those with underexploited synergies (Ib) as depicted in Figure 2. In a weakly integrated system with under-exploited synergies, the border, as such, is not that much of a substantial barrier. However, the possibilities for cross-border integration have for various

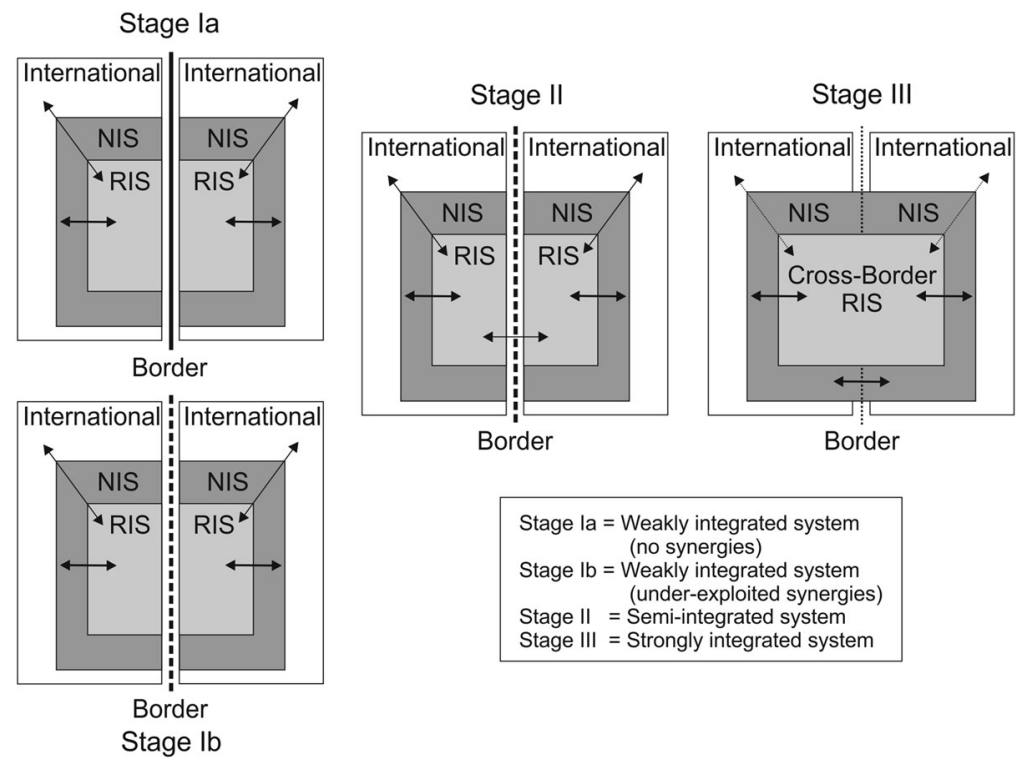

Figure 2. Different stages of CBRIS integration (modified from Lundquist \& Trippl, 2013). 
reasons not been taken advantage of: they include low social acceptance of CBC, strong embeddedness of actors in their RIS and NIS, differences in institutions as well as institutional thinness. ${ }^{5}$ They have, thus, remained under-utilized. This is a situation that can be addressed by policy instruments and exploited by businesses since there are evidently positive outcomes to be gained from CBC. In contrast, in the case of weakly integrated systems with no synergies, the border acts as such a strong barrier between the adjacent regions that there simply is very little that the opposing sides of the border could learn or gain from each other. The lack of synergies might also stem from having too much similarity, but intuitively this is less often the case for national borders. Depending on the CBR, the situation in weakly integrated systems with under-exploited synergies could be upgraded relatively easily. This is the case when the border is a physical barrier or a barrier related to laws and regulations (Lundquist \& Trippl, 2013). For example, Weidenfeld (2013) has suggested that tourism increases cross-border mobility. In some regions this can be the justification behind the development of better transport infrastructure, which removes physical barriers. However, when the border marks a barrier of a cognitive, cultural or linguistic nature, further integration is more likely to require substantial, sustained long-term efforts that offer only uncertain outcomes (Lundquist \& Trippl, 2013).

Semi-integrated systems exhibit strong CBC in narrow segments of the economy. Thus, a semi-integrated CBRIS might share a single highly networked cross-border cluster in a particular field. However, innovation networking is still not a region-wide phenomenon. Strongly integrated systems display stable mechanisms for cross-border policy coordination, significant cross-border flows of knowledge, high accessibility and intensity of cross-border mobility. Accordingly, they are characterized by dense cross-border innovation networks as well as several innovative cross-border clusters. Thus, the strongly integrated systems stage should be seen as the most advanced form of cross-border integration. At the same time, Lundquist and Trippl (2013) deem the last stage as the 'utopia' of CBRIS integration: although few regions might attain this final stage in some of the dimensions, it is quite unlikely that any single CBR would reach it in terms of all the CBRIS dimensions discussed above. In line with this, Trippl (2010) has assumed that there are only a few CBR in the world that might possess the favourable conditions for a highly integrated CBRIS.

However, it is extremely difficult to analyse integration because it takes place in a grey zone where there is a combination of formal and informal networks between a wide range of different actors (Lundquist \& Trippl, 2013; Lundquist \& Winther, 2006). Moreover, the conceptual literature on CBRIS has, thus far, largely overlooked the more nuanced view that underlies the macro-level integration dynamics, that is, the individuals involved in CBC (van den Broek \& Smulders, 2015). Consequently, to date the only notable empirical account of CBRIS integration has been offered by Hansen (2013), who concluded that the removal of an internal physical barrier ${ }^{6}$ in a CBR can have a substantial positive effect on integration if this is supported by 'a targeted policy effort' (discussed in Section 3.7). Contrarily, other studies have been constrained in analysing only the current stage of integration without time-series data or significant considerations of CBRIS integration as an evolutionary development process (Coenen et al., 2004; Koschatzky, 2000; Makkonen, 2015). 


\subsection{CBR in the CBRIS literature}

In line with the problematic of defining the contours of geographically distinct innovation systems (Doloreux \& Parto, 2005), the question of where to draw the 'borders' of a CBR is necessarily rather subjective. Thus, the issue of what constitutes an appropriate size for a CBR to be considered as a possible CBRIS is a question that has not been adequately discussed or clarified in the conceptual literature on CBRIS. The subjectivity is intensified by the loose definition of CBR as an area consisting of neighbouring territories, belonging to different nation states, where the proximity to the border directly and significantly affects economic and social life (Weidenfeld, 2013). To add precision, CBR, for example in the case of Euroregions, have also been specified as 'a bounded territorial unit composed of the territories of authorities participating in a CBC initiative' (Perkmann, 2003, p. 157). Nevertheless, many of the European CBR have started as, and still are, 'regions on paper' with huge differences in their socio-economic, cultural and institutional backgrounds (Paasi, 2002). Additionally, as noted already by Perkmann (1999), the large administrative units commonly applied, for example in the case of Euroregions, rarely fit the delineation of CBR as functional entities. However, delineating CBR without taking into account the regional administrative-statistical borders would impose serious challenges for statistical data-gathering procedures.

The problems related to multiple geographical scales have been discussed in a range of empirical CBRIS studies. Notably, opposing sides of a CBR belong to their respective, and commonly quite different, RIS and NIS (Coenen et al., 2004; Koschatzky, 2000; Lundquist $\&$ Winther, 2006). They also have wider global connections rather than just national or CBC linkages (Hansen, 2013). Since regional economies are not by any means closed systems (Uyarra \& Flanagan, 2010), these connections all ultimately impact on the collaboration patterns of regional actors and, thus, on the contemporary and achievable level of integration in any given CBR. Accordingly, as noted by van den Broek and Smulders (2014, p. 172): 'for regional actors, most regulative gaps are difficult to fill because decisions to change or create institutions are taken at higher levels'. Thus, discussing CBRIS as isolated entities without considering their wider national and global contexts could lead to a risk of enfolding the effects of integration with effects that depend on the individual regions' positions in NIS and global networks (Hansen, 2013; Lundquist \& Winther, 2006; Makkonen, 2015). In line with this, ignoring how individual cross-border actors and local companies actually implement and engage in CBC would undermine the true level of integration of CBRIS. This is particularly evident in the weakly integrated stage when $\mathrm{CBC}$ is still far from being an economy-wide phenomenon. Therefore, as evidenced in a study by van den Broek and Smulders (2015), if these vertical linkages are overlooked, even well-designed $\mathrm{CBC}$ projects can have minimal impacts in terms of institutional cross-border integration: the vertical linkages should be taken into account in both directions ('up' and 'down'), since it is evident that while national and international authorities can be highly influential in facilitating or hindering $\mathrm{CBC}$, the level of $\mathrm{CBC}$ is also determined by the decisions of local firms, policy-makers and other actors. Again, these actors are not homogenous across different CBRIS. Rather, 'similar actors can play very different roles ... across different systems' (Uyarra \& Flanagan, 2010 , p. 683). However, empirically the literature on CBRIS has largely by-passed these potential shortcomings and moreover concentrated on individual regions (Appendix). 
Consequently, it is striking that there is not a single published ${ }^{7}$ empirical study on CBRIS that has taken a comparative look at more than a single CBR.

\subsection{CBRIS and sectoral considerations}

As discussed above, a CBR with only a single cooperative cross-border cluster would at best constitute and be designated as a semi-integrated system. Thus, the CBRIS is a far more comprehensive approach in its attempt to encompass all the various industry sectors present in a CBR. In addition, it aims to take into account the Triple Helix academia-industry-government cooperation partnerships within the CBR (Etzkowitz, 2008; Jauhiainen, 2014). Still, empirically the concept has been approached precisely through single industry case studies. These range from the more general manufacturing and business service sectors (Koschatzky, 2000; Lundquist \& Winther, 2006) into specific high-tech fields of bio- and clean-technology (Coenen et al., 2004; Hansen, 2013; Kiryushin et al., 2013) and low-tech fields of horticulture (van den Broek \& Smulders, 2014, 2015) and the olive oil industry (Bijaoui et al., 2011). However, as a positive note, the analysis and discussion in these studies has commonly included both private- and the public-sector figures and viewpoints. Thus, at least the Triple Helix type of CBC has meticulously been taken into account in the empirical literature on CBRIS. Nevertheless, the only empirical study, thus far which has taken a wider perspective is that of Makkonen (2015), who has conducted an economywide exploration of the knowledge infrastructure in a Danish-German CBR. However, the metrics for $\mathrm{CBC}$ employed in the paper, that is scientific co-publications, poorly describe the level of knowledge flows outside the academia and high-tech sectors: instead of being central to the paper, the regional sectoral variety is only investigated through scientific research fields and scientific $\mathrm{CBC}$. Therefore, the empirical literature has yet to take a more comprehensive stance towards sectoral differences and their impacts on cooperation, integration and knowledge transfer in CBRIS.

\subsection{Policy implications}

The innovation systems concept was not developed merely as an academic concept but also as a tool for national and regional policy-makers to foster innovation (Asheim \& Coenen, 2006; Asheim, Coenen, \& Moodysson, 2015). Thus, the CBRIS literature has definite policy implications. However, in the case of complex settings such as the CBR, regional innovation performance is influenced by a multitude of actors from various spatial scales: local, regional, national and international (Lundquist \& Trippl, 2013; Trippl, 2010). This means that, to begin with, some regions might altogether lack the administrative and political bodies which are required for designing and implementing CBRIS policies (van den Broek \& Smulders, 2014). Furthermore, the fact that CBR belong to two, or more, separate national states complicates the development and execution of any policy efforts directed at promoting CBRIS integration (Lundquist \& Winther, 2006). Therefore, as stated by Trippl (2010, pp. 156-157): 'policy instruments and measures that are used to boost innovation in "conventional" RIS are also of relevance for enhancing the innovation capacity of CBR', but on the other hand 'specific types of barriers can make their appearance in CBRIS, calling for an extension of the traditional policy repertoire'. Thus, the following policy implications, presented in Table 1, have 
Table 1. Key policy suggestions for promoting CBRIS integration.

\begin{tabular}{|c|c|}
\hline Policy suggestion & Suggested by \\
\hline $\begin{array}{l}\text { Transfer experiences of role models and successful } \\
\text { collaborations }\end{array}$ & Koschatzky (2000), Lundquist and Trippl (2013) \\
\hline Stimulate related variety and knowledge interaction & $\begin{array}{l}\text { Coenen et al. (2004), Trippl (2010), Weidenfeld (2013), } \\
\text { Jauhiainen (2014) }\end{array}$ \\
\hline $\begin{array}{l}\text { Signal the importance of a CBRIS in attaining regional } \\
\text { competitiveness }\end{array}$ & Trippl (2010), Lundquist and Trippl (2013) \\
\hline Promote the emergence of a common regional identity & Trippl (2010) \\
\hline Build up bridging organizations & Trippl (2010), Hansen (2013) \\
\hline $\begin{array}{l}\text { Facilitate dialogue and consensus building in cross-border } \\
\text { policy networks }\end{array}$ & Trippl (2010), Lundquist and Trippl (2013) \\
\hline Improve accessibility & Lundquist and Trippl (2013) \\
\hline
\end{tabular}

been commonly advocated when discussing innovation promotion specifically in a CBR context (cf. OECD (2013), which provides very similar policy recommendations).

Lundquist and Trippl (2013) have further underlined that the policies should be different according to the integration stage of CBRIS. For CBRIS in stage Ia (weakly integrated with no synergies), issues other than innovation-related integration should be addressed initially, whereas for CBRIS in stage Ib (weakly integrated with under-exploited synergies), the focus should be on promoting acceptance of cross-border integration, fostering knowledge interaction, establishing cross-border governance structures and on improving accessibility. Naturally, further developments towards more integrated CBRIS will become increasingly more challenging. A key aspect should, thus, be the continuous strengthening, broadening and deepening of the integration processes, with an innovation policy portfolio that takes into account the various dimensions of CBRIS (Lundquist \& Trippl, 2013).

Relatively little empirical evidence exists on the effectiveness of these policy measures. This is due to the fact that there is not that much to analyse: Jauhiainen (2014) has stated that in the Baltic Sea Region, at least, cross-border innovation policies exist only on paper, and not in practice. However, there are two notable exceptions of empirical studies on CBRIS policies. First, van den Broek and Smulders (2014, 2015) have analysed policy documents, as a desk study, to underline specific institutional gaps that seem to hinder CBRIS integration. Second, Hansen (2013) has noted that when it comes to crossborder scientific collaboration, the investments made on transport infrastructure do not lead to a higher level of integration by themselves. Rather, Hansen (2013) points out that it is the combination of improved accessibility and the creation of cross-border organizations that will lead to increased CBC. This highlights the importance of bridging organizations as a policy tool for facilitating CBRIS integration (Hansen, 2013; Trippl, 2010). Still, relatively little is known whether and specifically how the varying proposed policy measures have been implemented, if at all, in CBR contexts. Furthermore, if implemented, it remains unclear how effective the policy measures have been in promoting CBRIS integration, calling for further research on the subject. ${ }^{8}$

\section{Discussion: the mismatch between the conceptual and empirical literature on CBRIS and directions for further research}

This review of the CBRIS literature has pointed out and examined the mismatch between the conceptual and empirical studies. The difficulties in applying the concept of CBRIS in 
empirical literature mainly stems from four intertwined issues: (1) the fuzziness inherent in the varying definitions of proximity, (2) the complexity of the various dimensions of CBRIS, (3) the difficulties in analysing the process of integration and (4) the lack of consensus in delineating CBRIS:

- Firstly, the integration of several proximity types into the CBRIS concept allows a differentiated view in a conceptual manner. However, this renders the empirical validation of the concept of proximity extremely difficult. Thus, the potential overlap between the proximity types, as revealed in Section 3.2, might not be adequate for empirical investigations, as evidenced by the fact that empirical studies of CBRIS have focused mainly on isolated proximity types. Consequently, the empirical literature has failed to answer how the proximity types interact with, and jointly impact on, CBRIS. This has led to the neglect of the potential interdependencies between them. Therefore, empirical research is required to validate the role of proximity types in the context of CBRIS. Moreover, when it comes to related variety, there are no readily available benchmarks to compare what is 'far enough, but not too close' in terms of cognitive proximity. This raises the question of the optimal degree of cognitive proximity, which might differ for various CBR and sectors. Again, there is no general consensus on the indicators to measure cognitive proximity. Thus, a commonly accepted operationalization that allows a comparable analysis of different CBR and sectors is required to deal with the question of related variety.

- Secondly, it is relatively simple to pinpoint conceptually the dimensions that constitute a CBRIS. However, this is not the case for the empirical analyses of these dimensions. Building extensive data-sets or collecting comprehensive qualitative material even for a single dimension of CBRIS is time consuming. Thus, empirically it is demanding to explore more than one dimension of CBRIS in a single study due to the amount of work that would be needed to gather the data. Consequently, comparative studies exploring several CBRIS dimensions with each other are almost non-existent as discussed in Section 3.3. As pointed out in Section 3.6, the same applies to any comparative studies aiming at incorporating and analysing several industrial sectors or clusters in a cross-border context. Thus, the interdependencies between the dimensions and their overall impact on the innovativeness and competitiveness of a CBR require empirical evidence. To adopt a firm perspective would be an approach to reduce this complexity for empirical analyses and to create valuable insights into the interplay of the different CBRIS dimensions. Further research might, therefore, benefit from concentrating on the knowledge application and exploitation dimension, that is, on the role of firms in CBRIS. The influence of the different dimensions on firm performance, and how firms themselves contribute to CBRIS are of particular interest.

- Thirdly, as identified in Sections 3.4 and 3.7, cross-border integration processes take place in a grey zone of formal and informal networks between a wide range of different institutional and individual actors from various spatial scales. The way that these complex networks should be defined and observed empirically, thus, remains problematic. Starting from a micro-level perspective and focus on the existing relationships of different actors might be a useful approach to grasp formal and informal networks. Additionally, an analysis of a time series that covers cross-border integration processes together with firm performance would be adequate to validate the value of integration that the CBRIS concept proposes. 
- Fourthly, the issue of what is the appropriate geographical delineation of CBRIS that empirical validations should utilize remains an unclarified issue, as shown in Section 3.5. On the one hand, when applying large administrative units as the regional scale of analysis, it usually follows that the preconditions of considering CBRIS as functional regions have to be relaxed. However, on the other hand, if these regional administrative-statistical borders are not taken advantage of, it will impose serious challenges for data collection. In addition, there are also vertical links in CBRIS integration involving, for example, a variety of local cross-border actors such as individual planners, policy-makers and companies as well as the nation states in question. Ignoring these actors, which are not homogenous across different CBRIS, and linkages will make it difficult to draw distinctions between the impacts of local/individual, regional and national efforts on CBRIS integration. Therefore, the question of what would constitute an appropriate size of a CBRIS to be applied in empirical studies, and how to empirically account for the vertical linkages that affect CBRIS, remain unresolved questions.

Additionally, as pointed out in Section 3.7, it seems that CBRIS literature has not yet penetrated itself into practise and into actual cross-border development policies. Therefore, empirical research on the effectiveness of CBRIS policy measures has remained rather limited. Future conceptual and empirical research should take into account the design, implementation and evaluation of policy measures to provide a differentiated set of policy tools that enable a more effective development of CBRIS in various CBR.

Taken together, these difficulties have led to a situation where the existing empirical literature on CBRIS has commonly concentrated on case study examples from individual industries and CBR, exploring only a single type of proximity and dimension of CBRIS integration as an ad hoc exercise without time-series data. Thus, the CBRIS concept lacks an integral empirical validation. For this purpose, a research agenda - based on the conducted CBRIS literature review - is formulated in the remaining Section 5.

\section{Concluding remarks: CBRIS research agenda}

The CBRIS literature was reviewed and scrutinized to discuss the reasons behind the observed mismatch between the conceptual and empirical literature: whereas the conceptual literature deals with CBRIS as a comprehensive analytical framework for discussing cross-border integration, the empirical literature has thus far lagged in terms of analytical rigour. Instead of focusing on CBRIS as an economy-wide phenomenon consisting of several intertwined dimensions, as suggested by the conceptual literature, the existing empirical literature has analysed CBRIS through individual dimensions, case studies from specific industry sectors and with limited geographical scope. This has hindered the possibilities of generalizing the results and validating the concept as a whole. The reasons behind this mismatch stem from the problems of treating the fuzzy and intangible concepts of proximity, integration and CBRIS dimensions empirically. The difficulties in delineating CBRIS geographically and the lack of existing CBRIS policies, add to this. Thus, a major problem in empirical CBRIS literature is the fact that collecting qualitative and quantitative data on the process of integration, various types of proximity and dimensions of CBRIS for the purposes of a comparative sectoral and/or regional analysis, surpassing the limitations of case studies, is extremely challenging and time consuming. 
However, to encourage further more integrative empirical literature on CBRIS, which would be the most effective way that the concept could be tested and developed, we indicate possible directions for further research. This research agenda includes the following. Initially, while challenging from a theoretical stance, it is necessary to define different proximity types in a way that they are suitable also for empirical purposes. These definitions should provide a clear empirical operationalization of the concept that avoids conceptual overlap. This work should also include a better conceptualization of the dynamics and interplay between the various types of proximity (Balland, Boschma, \& Frenken, 2015). To adopt a dynamic view of proximities could be a conceptual advancement for CBRIS analysis, because it may help us to better understand innovation-driven integration processes in CBR. Thus empirically, comprehensive and comparative time-series data are needed to validate the propositions laid in the earlier literature on proximity (and related variety). Additionally, the integral validation of the CBRIS concept requires empirical analyses that cover all dimensions of CBRIS. Therefore, an operationalization of the different dimensions and their interaction is required to open up this 'black box' of CBRIS literature. Methodologically converting the conceptual debate on CBRIS into an empirical investigation is challenging, since it requires data from various different sources and the integration of qualitative material with quantitative data. However, with a properly justified empirical framework and geographical delineation of prospective CBRIS, this should be accomplishable within the context of setting the stage for further analyses testing individual aspects of CBRIS in greater detail. With more empirical studies on the subject, the literature on CBRIS could tackle its shortcomings in relation to the weaknesses of its current policy conclusions, which are not yet based on actual empirical evidence, but rather only on conceptual discussion. Thus, for example a follow-up on the policy recommendations made in the publication by OECD (2013) could reveal how effective, if implemented, have the recommended actions been. At the moment, before designing sector-specific policy conclusions founded on a thin base of empirical evidence, it might be adequate to elaborate holistic development strategies for CBRIS and afterwards implement more specific sub-strategies to avoid overlapping or diverging development efforts. The CBRIS concept could, thus, profit from linking it with the path dependence theory (Asheim, Grillitsch, \& Trippl, 2015) to achieve more holistic strategies, which seem to be especially relevant for CBRIS due to their heterogeneous characteristics (Lundquist \& Trippl, 2013).

The proposed research agenda summarizes the corner stones of a comprehensive analytical framework that would allow an integral empirical validation of the CBRIS concept. When it comes to facilitating the development of CBR, this could potentially lead to stronger policy conclusions that would be more strongly evidence-based. However, a realization of the research agenda is ambitious and beyond the scope of this article. Thus, the research agenda serves as a guideline for future research which aims at developing an improved understanding of innovation processes in CBR and of the CBRIS concept itself.

\section{Notes}

1. To be precise, Trippl already made early attempts to conceptualise CBRIS in a working paper in 2006 (Trippl, 2006).

2. Also referred to as 'trans-frontier innovation systems' (Lundquist \& Trippl, 2013). 
3. To be precise, Coenen and his colleagues had presented an earlier draft of the paper at the 4th Congress on Proximity Economics held in Marseille, 17-18 June 2004.

4. Breakthrough innovations could, however, potentially turn this 'unrelated variety' into related variety (Castaldi, Frenken, \& Los, 2014).

5. Institutional thickness in a locality is made up of strong institutional and organisational presence (e.g. firms, trade associations, etc.), the high level of interaction between these institutions and organizations, their power relations and (potential) common agendas (Amin \& Thrift, 1994; Henry \& Pinch, 2001), whereas institutional thinness can be caused for example by a lack of organizations and institutions, a lack of common vision, few interactions, imbalanced power relations, joint visions that oppose renewal efforts, closed networks, etc. However, an assessment of the absolute difference between institutional thinness and thickness remains challenging (Zukauskaite, Plechero, \& Trippl, 2016).

6. Here, the removal of the physical barrier refers to the opening of the Öresund Bridge in 2000.

7. However, there is a working paper by Lundquist and Trippl (2009) with rudimental empirical comparisons between the Öresund region and the Centrope area and a series of descriptive profiles of innovative activities in certain CBR published by the OECD (2013).

8. A recent working paper by Muller, Zenker, Hufnagl, Héraud, and Schnabl (2015) has drawn a similar conclusion.

\section{Acknowledgements}

We are grateful to Professor Allan Williams and to the anonymous referees for their comments on improving the content of the manuscript.

\section{Disclosure statement}

No potential conflict of interest was reported by the authors.

\section{Funding information}

This work was supported by the Marie Curie Actions (Intra-European Fellowship for career development) within the Seventh Framework Programme (FP7) of the EU under Grant PIEF-GA-2013624930 and by the project 'Emerging Attraction' within the programme INTERREG 4A Syddanmark-Schleswig-K.E.R.N. in the context of the European Regional Development Fund.

\section{ORCID}

Teemu Makkonen (ํ) http://orcid.org/0000-0002-1065-1806

\section{References}

Aguilera, A., Lethiais, V., \& Rallet, A. (2015). Spatial proximity and intercompany communication: Myths and realities. European Planning Studies, 23, 798-810. doi:10.1080/09654313.2014.979137

Amin, A., \& Thrift, N. (Eds.). (1994). Globalization, institutions, and regional development in Europe. Oxford: Oxford University Press.

Asheim, B., \& Coenen, L. (2006). Contextualising regional innovation systems in a globalising learning economy: On knowledge bases and institutional frameworks. Journal of Technology Transfer, 31, 163-173. doi:10.1007/s10961-005-5028-0

Asheim, B., Coenen, L., \& Moodysson, J. (2015). Methods and applications of regional innovation systems analysis. In C. Karlsson, M. Andersson, \& T. Norman (Eds.), Handbook of research methods and applications in economic geography (pp. 272-290). Cheltenham: Edward Elgar. 
Asheim, B., Grillitsch, M., \& Trippl, M. (2015). Regional innovation systems: Past-presence-future. Circle Papers in Innovation Studies, 2015(36), 1-19.

Asheim, B., \& Vang, J. (2006). Regional innovation systems in Asian countries: A new way of exploiting the benefits of transnational corporations. Innovation: Management, Policy \& Practice, 8, 27-44. doi:10.5172/impp.2006.8.1-2.27

Autio, E. (1998). Evaluation of RTD in regional systems of innovation. European Planning Studies, 6, 131-140. doi:10.1080/09654319808720451

Balland, P.-A., Boschma, R., \& Frenken, K. (2015). Proximity and innovation: From statics to dynamics. Regional Studies, 49, 907-920. doi:10.1080/00343404.2014.883598

Bijaoui, I., Sultan, S., \& Tarba, S. (2011). The progressive model, an economic reconciliation process for regions in conflict. Cross Cultural Management: An International Journal, 18, 293-312. doi:10.1108/13527601111152833

Boschma, R. (2005). Proximity and innovation: A critical assessment. Regional Studies, 39, 61-74. doi: $10.1080 / 0034340052000320887$

Boschma, R., \& Weterings, A. (2005). The effect of regional differences on the performance of software firms in the Netherlands. Journal of Economic Geography, 5, 567-588. doi:10.1093/jeg/lbh074

van den Broek, J., \& Smulders, H. (2014). Institutional gaps in cross-border regional innovation systems: The horticultural industry in Venlo-Lower Rhine. In R. Rutten, P. Benneworth, D. Irawati \& F. Boekema (Eds.), The social dynamics of innovation networks (pp. 157-176). Abingdon: Routledge.

van den Broek, J., \& Smulders, H. (2015). Institutional hindrances in cross-border regional innovation systems. Regional Studies, Regional Science, 2, 116-122. doi:10.1080/21681376.2015. 1007158

Broekel, T. (2015). The co-evolution of proximities: A network level study. Regional Studies, 49, 921-935. doi:10.1080/00343404.2014.1001732

Broekel, T., \& Boschma, R. (2012). Knowledge networks in the Dutch aviation industry: The proximity paradox. Journal of Economic Geography, 12, 409-433. doi:10.1093/jeg/lbr010

Brusco, S. (1982). The Emilian model: Productive decentralisation and social integration. Cambridge Journal of Economics, 6, 167-184.

Caragliu, A., de Dominicis, L., \& de Groot, H. (2016). Both Marshall and Jacobs were Right! Economic Geography, 92, 87-111. doi:10.1080/00130095.2015.1094371

Castaldi, C., Frenken, K., \& Los, B. (2014). Related variety, unrelated variety and technological breakthroughs: An analysis of US state-level patenting. Regional Studies, 49, 767-781. doi:10. 1080/00343404.2014.940305

Coenen, L., Moodysson, J., \& Asheim, B. (2004). Nodes, networks and proximities: On the knowledge dynamics of the Medicon Valley biotech cluster. European Planning Studies, 12, 1003-1018. doi:10.1080/0965431042000267876

Cooke, P. (1992). Regional innovation systems: Competitive regulation in the new Europe. Geoforum, 23, 365-382. doi:10.1016/0016-7185(92)90048-9

Doloreux, D., \& Parto, S. (2005). Regional innovation systems: Current discourse and unresolved issues. Technology in Society, 27, 133-153. doi:10.1016/j.techsoc.2005.01.002

Etzkowitz, H. (2008). The triple helix. New York, NY: Routledge.

Hansen, T. (2013). Bridging regional innovation: Cross-border collaboration in the Øresund region. Geografisk Tidsskrift-Danish Journal of Geography, 113, 25-38. doi:10.1080/00167223.2013. 781306

Hansen, T., \& Hansen, R. (2006). Integration of the scientific community as exemplified by the biotech sector: An analysis based on bibliometric indicators in the Danish-Swedish border region. GeoJournal, 67, 241-252. doi:10.1007/s10708-007-9057-0

Hartog, M., Boschma, R., \& Sotarauta, M. (2012). The impact of related variety on regional employment growth in Finland 1993-2006: High-tech versus medium/low-tech. Industry and Innovation, 19, 459-476. doi:10.1080/13662716.2012.718874

Hassink, R., Dankbaar, B., \& Corvers, F. (1995). Technology networking in border regions: Case study of the Euregion Maas-Rhine. European Planning Studies, 3, 63-83. doi:10.1080/ 09654319508720290 
Henry, N., \& Pinch, S. (2001). Neo-Marshallian nodes, institutional thickness, and Britain's 'motor sport valley': Thick or thin? Environment and Planning A, 33, 1169-1183. doi:10.1068/a32184

Heringa, P., Horlings, E., van der Zouwen, M., van den Besselaar, P., \& van Vierssen, W. (2014). How do dimensions of proximity relate to the outcomes of collaboration? A survey of knowledge-intensive networks in the Dutch water sector. Economics of Innovation and New Technology, 23, 689-716. doi:10.1080/10438599.2014.882139

Hussler, C. (2004). Culture and knowledge spillovers in Europe: New perspectives for innovation and convergence policies. Economics of Innovation and New Technology, 13, 523-541. doi:10. 1080/1043859042000234302

Jauhiainen, J. (2014). Baltic Sea region innovation systems: Challenges and opportunities. Baltic Sea Region Policy Briefing, 2(1), 63-73.

Kiryushin, P., Mulloth, B., \& Iakovleva, T. (2013). Developing cross-border regional innovation systems with clean technology entrepreneurship: The case of Øresund. International Journal of Innovation and Regional Development, 5, 179-195. doi:10.1504/IJIRD.2013.055237

Knoben, J., \& Oerlemans, L. (2006). Proximity and inter-organizational collaboration: A literature review. International Journal of Management Reviews, 8, 71-89. doi:10.1111/j.1468-2370.2006. 00121.x

Koschatzky, K. (2000). A river is a river: Cross-border networking between Baden and Alsace. European Planning Studies, 8, 429-449. doi:10.1080/713666422

Krätke, S., \& Borst, R. (2007). EU eastern enlargement and the configuration of German-Polish inter-firm linkages. Tijdschrift voor economische en sociale geografie, 98, 621-640. doi:10.1111/ j.1467-9663.2007.00429.x

Lundquist, K.-J., \& Trippl, M. (2009). Towards cross-border innovation spaces. SRE-Discussion Papers, 2009(5), 1-34.

Lundquist, K.-J., \& Trippl, M. (2013). Distance, proximity and types of cross-border innovation systems: A conceptual analysis. Regional Studies, 47, 450-460. doi:10.1080/00343404.2011. 560933

Lundquist, K.-J., \& Winther, L. (2006). The interspace between Denmark and Sweden: The industrial dynamics of the Öresund cross-border region. Geografisk Tidsskrift-Danish Journal of Geography, 106, 115-129. doi:10.1080/00167223.2006.10649549

Lundvall, B.-Å. (Ed.). (1992). National systems of innovation. London: Pinter.

Lundvall, B.-Å. (2007). National innovation systems: Analytical concept and development tool. Industry and Innovation, 14, 95-119. doi:10.1080/13662710601130863

Maggioni, M., \& Uberti, E. (2007). Inter-regional knowledge flows in Europe: An econometric analysis. In K. Frenken (Ed.), Applied evolutionary economics and economic geography (pp. 230-255). Cheltenham: Edward Elgar.

Makkonen, T. (2015). Scientific collaboration in the Danish-German border region of Southern Jutland-Schleswig. Geografisk Tidsskrift-Danish Journal of Geography, 115, 27-38. doi:10. 1080/00167223.2015.1011180

Makkonen, T., \& Inkinen, T. (2014). Spatial scaling of regional strategic programmes in Finland: A qualitative study of clusters and innovation systems. Norsk Geografisk Tidsskrift - Norwegian Journal of Geography, 68, 216-227. doi:10.1080/00291951.2014.924551

Maskell, P., \& Törnqvist, G. (1999). Building a cross-border learning region. Copenhagen: Copenhagen Business School Press.

McCann, P., \& Ortega-Argilés, R. (2013). Modern regional innovation policy. Cambridge Journal of Regions, Economy and Society, 6, 187-216. doi:10.1093/cjres/rst007

Moodysson, J., \& Jonsson, O. (2007). Knowledge collaboration and proximity: The spatial organization of biotech innovation projects. European Urban and Regional Studies, 14, 115-131. doi:10.1177/0969776407075556

Muller, E., Zenker, A., Hufnagl, M., Héraud, J.-A., \& Schnabl, E. (2015). Cross-border integration of regional innovation systems and smart specialisation strategies. evoReg Research Note, 29, 1-16.

Nooteboom, B., van Haverbeke, W., Duysters, G., Gilsing, V., \& van den Oord, A. (2007). Optimal cognitive distance and absorptive capacity. Research Policy, 36, 1016-1034. doi:10.1016/j.respol. 2007.04.003 
OECD. (2013). Regions and innovation: Collaborating across borders. Paris: Author.

van Oort, F., de Geus, S., \& Dogaru, T. (2015). Related variety and regional economic growth in a cross-section of European urban regions. European Planning Studies, 23, 1110-1127. doi:10. 1080/09654313.2014.905003

Paasi, A. (2002). Regional transformation in the European context: Notes on regions, boundaries and identity. Space and Polity, 6, 197-201. doi:10.1080/1356257022000003626

Paci, R., Marrocu, E., \& Usai, S. (2014). The complementary effects of proximity dimensions on knowledge spillovers. Spatial Economic Analysis, 9, 9-30. doi:10.1080/17421772.2013.856518

Perkmann, M. (1999). Building governance institutions across European borders. Regional Studies, 33, 657-667. doi:10.1080/00343409950078693

Perkmann, M. (2003). Cross-border regions in Europe: Significance and drivers of regional crossborder co-operation. European Urban and Regional Studies, 10, 153-171. doi:10.1177/ 0969776403010002004

Porter, M. (1990). The competitive advantage of nations. London: MacMillan.

Rohde, S. (in press). Industry clusters across national borders: Literature review and research deficits. International Journal of Entrepreneurship and Small Business.

Tödtling, F., \& Trippl, M. (2005). One size fits all? Towards a differentiated regional innovation policy approach. Research Policy, 34, 1203-1219. doi:10.1016/j.respol.2005.01.018

Trippl, M. (2006). Cross-border regional innovation systems. SRE-Discussion Papers, 2006(5), 1-26.

Trippl, M. (2010). Developing cross-border regional innovation systems: Key factors and challenges. Tijdschrift voor economische en sociale geografie, 101, 150-160. doi:10.1111/j.14679663.2009.00522.x

Trippl, M. (2012). Innovation networks in a cross-border context: The case of Vienna. In M. van Geenhuizen \& P. Nijkamp (Eds.), Creative knowledge cities (pp. 273-302). Cheltenham: Edward Elgar.

Uyarra, E., \& Flanagan, K. (2010). From regional systems of innovation to regions as innovation policy spaces. Environment and Planning C: Government and Policy, 28, 681-695. doi:10. 1068/c0961

Weidenfeld, A. (2013). Tourism and cross border regional innovation systems. Annals of Tourism Research, 42, 191-213. doi:10.1016/j.annals.2013.01.003

Zukauskaite, E., Plechero, M., \& Trippl, M. (2016). Institutional thickness revisited. Circle Papers in Innovation Studies, 2016(1), 1-35. 


\section{Appendix}

Table A1. The reviewed literature.

\begin{tabular}{|c|c|c|c|c|c|c|c|}
\hline & Method & Data & Geographical scale & Sectoral scope & Proximity types & Studied dimension & Selected conclusions* \\
\hline \multicolumn{8}{|c|}{ Early CBRIS literature: } \\
\hline $\begin{array}{l}\text { Koschatzky } \\
(2000)\end{array}$ & Quantitative & Survey & $\begin{array}{l}\text { Baden-Alsace (DE- } \\
\quad \text { FR) }\end{array}$ & $\begin{array}{l}\text { Manufacturing; } \\
\text { Business services }\end{array}$ & $\begin{array}{l}\text { Cultural; } \\
\text { Functional; } \\
\text { Institutional }\end{array}$ & NA & $\begin{array}{l}\text { '... for many firms innovation-relevant learning still } \\
\text { takes place mainly within their own national and } \\
\text { regional system of innovation' }\end{array}$ \\
\hline $\begin{array}{l}\text { Coenen et al. } \\
\text { (2004) }\end{array}$ & Quantitative & $\begin{array}{l}\text { Science Citation } \\
\text { Index }\end{array}$ & Öresund (DK-SE) & Biotechnology & $\begin{array}{l}\text { Functional; } \\
\quad \text { Relational }\end{array}$ & NA & $\begin{array}{l}\text { '... the cluster is embedded in two nationally } \\
\text { demarcated RIS, clearly shown by the limited cross- } \\
\text { border integration' }\end{array}$ \\
\hline $\begin{array}{l}\text { Lundquist and } \\
\text { Winther (2006) }\end{array}$ & Quantitative & $\begin{array}{l}\text { Statistics } \\
\text { Denmark; } \\
\text { Statistics } \\
\text { Sweden }\end{array}$ & Öresund (DK-SE) & Manufacturing & $\begin{array}{l}\text { Cultural; } \\
\text { Functional; } \\
\text { Social }\end{array}$ & NA & $\begin{array}{l}\text { 'The national development and the position in the } \\
\text { urban and regional systems are vital explanations } \\
\text { of the development of manufacturing sectors in } \\
\text { the Öresund region' }\end{array}$ \\
\hline \multicolumn{8}{|c|}{ Conceptual groundwork of CBRIS, discussion and further developments: } \\
\hline Trippl (2010) & Conceptual & NA & NA & NA & Multiple & Multiple & $\begin{array}{l}\text { '... cross-border areas differ enormously regarding } \\
\text { their capacity to develop an integrated innovation } \\
\text { space' and ' } \ldots \text { only a few cross-border areas will } \\
\text { represent favourable environments for establishing } \\
\text { a strong CBRIS' }\end{array}$ \\
\hline $\begin{array}{l}\text { Lundquist and } \\
\text { Trippl (2013) }\end{array}$ & Conceptual & NA & NA & NA & Multiple & Multiple & $\begin{array}{l}\text { '... in the real world it is probably very hard for most } \\
\text { CBR to meet the final stage of integration' }\end{array}$ \\
\hline $\begin{array}{l}\text { Weidenfeld } \\
\text { (2013) }\end{array}$ & Conceptual & NA & NA & Tourism & Multiple & Multiple & $\begin{array}{l}\text { '... tourism is an enabler and a contributor to } \\
\text { knowledge transfer and innovation in CBR' }\end{array}$ \\
\hline $\begin{array}{l}\text { Jauhiainen } \\
\text { (2014) }\end{array}$ & Conceptual & NA & Baltic Sea Region & NA & Cognitive & Governance & $\begin{array}{l}\text { 'Instead of general policies making cross-border areas } \\
\text { internally similar, the policies in Baltic Sea Region } \\
\text { should facilitate cross-border innovation systems } \\
\text { with trans-frontier knowledge creation based on } \\
\text { positive difference' }\end{array}$ \\
\hline \multicolumn{8}{|c|}{ Empirical validations of CBRIS: } \\
\hline $\begin{array}{l}\text { Bijaoui et al. } \\
\text { (2011) }\end{array}$ & Quantitative & Interviews & $\begin{array}{l}\text { Galilee-Northern } \\
\text { West Bank } \\
\text { (IL-PS) }\end{array}$ & Olive oil sector & Functional & NA & $\begin{array}{l}\text { '... bottom-up decision-making process is the only } \\
\text { way at the moment for initiating the cluster and RIS } \\
\text { models in the olive sector' }\end{array}$ \\
\hline
\end{tabular}

(Continued) 
Table A1. Continued.

\begin{tabular}{|c|c|c|c|c|c|c|c|}
\hline & Method & Data & Geographical scale & Sectoral scope & Proximity types & Studied dimension & Selected conclusions* \\
\hline Hansen (2013) & Quantitative & $\begin{array}{l}\text { Web of } \\
\text { Knowledge }\end{array}$ & Öresund (DK-SE) & Biotechnology & Functional & $\begin{array}{l}\text { Knowledge } \\
\text { infrastructure; } \\
\text { Relational }\end{array}$ & $\begin{array}{l}\text { '... the removal of internal physical barriers in a CBR } \\
\text { can have a substantial and long-term positive } \\
\text { effect on knowledge flows if a targeted policy } \\
\text { effort is made. In the absence of such policies, no } \\
\text { effect is found' }\end{array}$ \\
\hline $\begin{array}{l}\text { Kiryushin et al. } \\
\text { (2013) }\end{array}$ & Qualitative & Interviews & Öresund (DK-SE) & Cleantech & Functional & NA & $\begin{array}{l}\text { '... encouraging research-based innovations related } \\
\text { to social sciences significantly extends the } \\
\text { possibility of building robust RIS' }\end{array}$ \\
\hline $\begin{array}{l}\text { van den Broek } \\
\text { and Smulders } \\
(2014)\end{array}$ & Qualitative & $\begin{array}{l}\text { Interviews; Desk } \\
\text { research }\end{array}$ & $\begin{array}{l}\text { Venlo-Lower } \\
\text { Rhine (NL-DE) }\end{array}$ & Horticulture & Institutional & $\begin{array}{l}\text { Socio-institutional; } \\
\text { Governance }\end{array}$ & $\begin{array}{l}\text { 'For regional actors, most regulative gaps are difficult } \\
\text { to fill because decisions to change or create } \\
\text { institutions are taken at higher levels' }\end{array}$ \\
\hline Makkonen (2015) & Quantitative & Web of Science & $\begin{array}{l}\text { Southern Jutland- } \\
\text { Schleswig (DK- } \\
\text { DE) }\end{array}$ & NA & Cognitive & $\begin{array}{l}\text { Knowledge } \\
\text { infrastructure; } \\
\text { Relational }\end{array}$ & $\begin{array}{l}\text { '... the adjacent side of the border is (often) } \\
\text { bypassed } \ldots \text { when searching for collaboration } \\
\text { partners' }\end{array}$ \\
\hline $\begin{array}{l}\text { van den Broek } \\
\text { and Smulders } \\
\text { (2015) }\end{array}$ & Qualitative & $\begin{array}{l}\text { Interviews; Desk } \\
\text { research }\end{array}$ & $\begin{array}{l}\text { Venlo-Lower } \\
\text { Rhine (NL-DE) }\end{array}$ & Horticulture & Institutional & $\begin{array}{l}\text { Socio-institutional; } \\
\text { Governance }\end{array}$ & $\begin{array}{l}\text { 'The embeddedness of actors in their respective } \\
\text { institutional architectures can help to explain how } \\
\text { cooperation problems occur, and how this impedes } \\
\text { integration of CBRIS...' }\end{array}$ \\
\hline
\end{tabular}

*Text in italics added by the authors for clarity. 